\title{
ПРИМЕР ДИГЕННОГО НАСЛЕДОВАНИЯ ПРИ МОDУ ДИАБЕТЕ: ОПИСАНИЕ КЛИНИЧЕСКОГО СЛУЧАЯ
}

\author{
Овсянникова А.К., Шахтшнейдер Е.В., Иванощук Д.Е., Рымар О.Д. \\ НИИТПМ - филиал ИЦиГ СО РАН, Новосибирск
}

Сахарный диабет (СД) типа MODY (maturity onset diabetes of the young: диабет взрослого типа у молодых) - моногенная форма заболевания, распространенность которой среди всех форм СД составляет 1-6\%.В большинстве случаев происходит наследование мутации в одном гене, однако, когда клинические проявления нетипичны для диагностированного типа MODY, следует провести молекулярно-генетическое исследование (МГИ) других генов.

ОПИСАНИЕ КЛИНИЧЕСКОГО СЛУЧАЯ: гипергликемия у 27-летней женщины без ожирения была обнаружена в первом триместре третьей беременности в ноябре 2015 года (уровень глюкозы в плазме 5,8 ммоль/л натощак). Был установлен диагноз гестационного диабета, инициирована инсулинотерапия в базис-болюсном режиме.

После родов в течение двух месяцев уровень глюкозы в крови находился в норме, затем вновь появилась гипергликемия до 10-15 ммоль/л. Была назначена терапия пероральными сахароснижающими препаратами (метформин и глимепирид). Ввиду незначительного ответа на терапию был назначен базальный инсулин в сочетании с ингибитором DPP-4 ситаглиптином и ингибитором SGLT2 эмпаглифлозином. В октябре 2016 года анализ на антитела к бета-клеткам поджелудочной железы и к глутаматдекарбоксилазе был отрицательным, уровень C-пептида составлял 553 пмоль/л натощак (норма: 298-2350 пмоль/л) натощак и 1129 пмоль/л после еды. Наследственный анамнез по СД не отягощен.

В сентябре 2017 года при молекулярно-генетическом обследовании была выявлена мутация в гене HNF1B (rs138986885), диагностирован вариант MODY5. Никаких других клинических фенотипов, связанных с мутациями в HNF1B, включая пороки развития мочеполовой системы или поражение почек, обнаружено не было. При обследовании членов семьи та же мутация в гене HNF1B была обнаружена у матери и дочери пробанда, не имеющих гипергликемии.

В сентябре 2017 года уровень глюкозы в крови повысился до 15-16 ммоль/л, а концентрация С-пептида натощак снизилась до 83 пмоль/л. Таблетированная сахароснижающая терапия была отменена и начата базис-болюсная инсулинотерапия гларгином (суточная доза 0,63 ЕД/кг), на этом фоне были достигнуты целевые показатели гликемии.

В январе 2019 года при обследовании уровень $\mathrm{HbA}_{1 c}$ 7,13\%. Отмечено дальнейшее снижение функции клеток поджелудочной железы: С-пептид натощак 33,3 пмоль/л, после еды 91,9 пмоль/л. Пациентке предложен перевод на помповую инсулинотерапию для улучшения качества жизни, снижения вариабельности гликемии в течение суток.

Так как у пациентки наблюдалось быстро прогрессирующее течение СД с быстрым снижением секреторной активности b-клеток характерная для сахарного диабета 1 типа проведено МГИ дополнительных генов, ассоциированных с нарушениями углеводного обмена. Верифицирован гетерозиготный вариант rs2476601 в гене тирозин-фосфатазы (PTPN22), который связан с повышенным риском развития СД 1 типа. У матери и дочери пробанда, которые являются носителями мутации в гене HNF1B, мутация в гене PTPN22 не обнаружена.

ВЫВОды: настоящее наблюдение демонстрирует быстрое снижение эндогенной продукции инсулина и прогрессирующее течение СД, связанного с мутациями в двух генах. 